\title{
Boehmite nanopowder recovered from aluminum cans waste as a potential adsorbent for the treatment of oilfield produced water
}

\author{
Adel Abdelkader ${ }^{1} \cdot$ Basem M. Hussien $^{2} \cdot$ Eman M. Fawzy $^{2} \cdot$ Asma A. Ibrahim $^{2}$
}

Received: 10 December 2020 / Accepted: 17 February 2021 / Published online: 9 March 2021

(c) The Author(s) 2021

\begin{abstract}
In the present study, high surface area boehmite nanopowder was recovered from aluminum cans waste. The sodium aluminate solution was first prepared by dissolving aluminum cans in $\mathrm{NaOH}$ solution and then, $\mathrm{H}_{2} \mathrm{O}_{2}$ solution was added to precipitate boehmite. The prepared boehmite was characterized by means of X-ray diffraction (XRD), transmission electron microscopy (TEM) and $\mathrm{N}_{2}$ adsorption-desorption techniques. The thermal stability of the boehmite sample was investigated using thermogravimetry (TG) and differential scanning calorimetry (DSC) techniques. The feasibility of using the prepared boehmite powder as a new low-cost adsorbent for the treatment of oilfield produced water was investigated. For comparison, commercial activated carbon was used for the treatment of the produced water under the same conditions. The efficiency of both of boehmite and activated carbon in the treatment of produced water was determined by monitoring the values of a number of pollution indicators [i.e. turbidity, sulfides, sulfates, total organic carbon (TOC), total petroleum hydrocarbon (TPH), and chemical oxygen demand (COD)] before and after the treatment. The boehmite powder showed very good efficiency in the treatment of the produced water, which is very close to that of commercial activated carbon under the same conditions. The effect of adsorbent dose, treatment time, and $\mathrm{pH}$ of the media on the adsorption efficiency of both of boehmite and activated carbon was examined at room temperature using chemical oxygen demand as a pollution indicator. The maximum capacity for COD reduction was $69.6 \%$ for boehmite and $83.5 \%$ for activated carbon at $40 \mathrm{~g} / \mathrm{l}$ adsorbent dosage, $\mathrm{pH} 7$, and 24-h contact time.
\end{abstract}

\section{Graphic abstract}

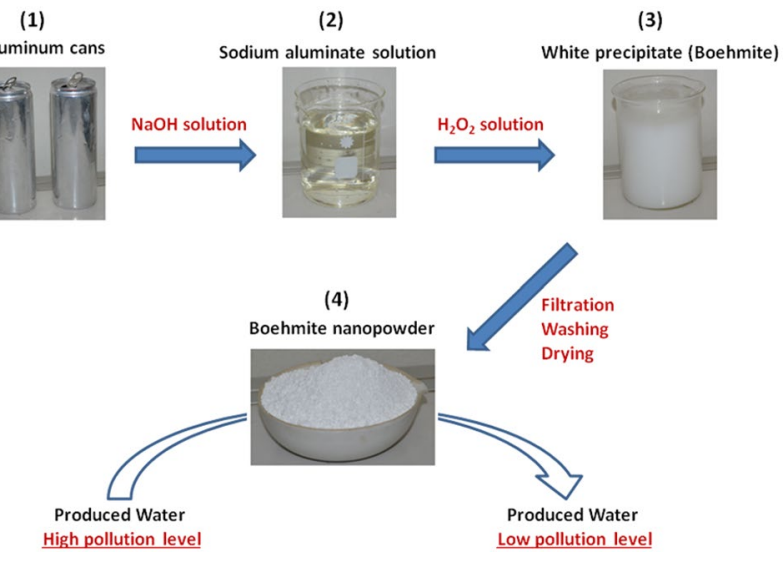

Keywords Aluminum cans $\cdot$ Boehmite $\cdot$ Nanopowder $\cdot$ Produced water $\cdot$ Waste

Adel Abdelkader

adel.abdelkader@sci.svu.edu.eg

Extended author information available on the last page of the article 


\section{Introduction}

Recycling of solid waste is a necessary and essential need nowadays to protect the human health and the surrounding environment and to utilize the natural resources in an effective way. The rapid growth in population caused a notable increase in the rate of waste generation which is the main reason for many of health and environmental problems [1,2]. So that, it is very important to find a suitable ways to valorize and expand the life cycle of these huge amounts of solid waste generated every day and everywhere. Among the solid wastes produced worldwide, aluminum solid wastes represent a major category. These aluminum solid wastes come from different sources, e.g., aluminum cans, aluminum foil, appliances, aluminum doors, flexible packaging, etc. [3]. More than $80 \%$ of the aluminum solid wastes come from the used aluminum cans and the remaining $20 \%$ comes from the other aluminum containing solid wastes [4]. About 475 billion aluminum beverage can are generated every year in which the pure aluminum metal content is about $97 \%$ [5]. Since the aluminum cans forms the majority of aluminum solid wastes, the studies must focus on the valorization and recycling of these cans by all possible economical ways.

The same as recycling of solid waste, the treatment of wastewater is also a necessary and essential need nowadays [6]. All the living organisms need water, so that, the pollution of water is one of the most important serious problems that faces all the world. The production of oil and gas in the oilfields in Egypt and other fossil fuel producing countries is accompanied with the production of large amounts of oil-contaminated wastewater which called produced water $(\mathrm{PW})$. The global onshore and offshore production of PW in 2015 was about 300 million barrels per day [7]. The characteristics and the degree of pollution of PW depend on many factors such as lifetime and type of the reservoirs in addition to the seasonal variations, production facility and formation structure. In general, PW contains pollutants, such as organic compounds, dissolved/suspended solids, and heavy metals $[8,9]$. PW is recycled by different ways including the injection into underground to increase oil production in the oilfields which is the main recycling way, in addition to other useful applications such as the use for irrigation and industry $[7,10]$. For countries that have limited resources of freshwater, the treatment of the large amounts of PW represents a good way for the supplementation of their resources of freshwater [11]. In many places, if there is no possible recycling or reuse strategy, the oilfield PW is discharged to the surrounding environment [10]. Unfortunately, more than $90 \%$ of PW in the offshore production is discharged to surface water which represents a serious threat to the marine environment [12]. Before the recycling or discharging of the produced water, there are a permitted pollution limits that must be meted [7]. So that, the treatment of $\mathrm{PW}$ is essential to comply with the permitted pollution limits required for the PW to be recycled or disposed. The decontamination of PW can be carried out through various physical, chemical, and biological methods depending on the technical and economical factors [7, 13-15]. However, the removal of the PW pollutants by adsorption using suitable solid adsorbents is considered as a promising treatment method among all the used methods. The use of adsorption processes has many advantages over the other techniques including the low cost, the ease of operation, the simplicity of the used design, the insensitivity to toxic pollutants, and the low number of by-products [16].

The aim of the present work is to achieve two important and useful goals. The first goal of this study is to convert aluminum can waste as one of the most important and widely generated solid wastes to a valuable material. In a previous study [5], we used aluminum cans to produce mesoporous $\gamma-\mathrm{Al}_{2} \mathrm{O}_{3}$ which was used as catalyst for the dehydration of methanol to dimethyl ether. The preparation method involved dissolving of aluminum cans in $\mathrm{HCl}$ solution followed by the precipitation of boehmite using $\mathrm{NH}_{4} \mathrm{OH}$ or $\mathrm{NaOH}$ solution. The dry boehmite was then calcined at $550{ }^{\circ} \mathrm{C}$ for $2 \mathrm{~h}$ to produce $\gamma-\mathrm{Al}_{2} \mathrm{O}_{3}$. In the present study, aluminum cans were treated in a different way to produce high surface area boehmite nanopowder. Boehmite (AlOOH) is an aluminum oxy-hydroxide which is one of the most important hydroxides due to its applications in catalysis and adsorption fields $[10,17-19]$. In addition, boehmite is a start material of the preparation of different kinds of catalysts, adsorbent materials, and optical materials. The most important calcination product of boehmite is $\gamma-\mathrm{Al}_{2} \mathrm{O}_{3}$ which has a great industrial importance and frequently used as adsorbents, catalysts and catalyst supports. In addition, boehmite is used in the preparation of templates which is used in the synthesis of core/shell materials [17-20]. The preparation of boehmite from aluminum cans in this study was carried out using a preparation method devised in our laboratory by El-Katatny et al. [21] and was used for the preparation of $\gamma-\mathrm{Al}_{2} \mathrm{O}_{3}$ from industrial aluminum wastes (i.e., aluminum dross tailings). According to El-Katatny's method, the aluminum metal is first dissolved in $\mathrm{NaOH}$ solution to form sodium aluminate solution which is then treated with $\mathrm{H}_{2} \mathrm{O}_{2}$ solution to precipitate boehmite. It is important to note that dissolving aluminum in $\mathrm{NaOH}$ solution to produce the sodium aluminate represents a bifunctional chemical process because it gives sodium aluminate and produces low-cost hydrogen at the same time [22, 23]. In addition, this devised process does not introduce an extraneous $\mathrm{H}_{2} \mathrm{O}_{2}$ anion compared with most of the neutralization precipitation methods. Furthermore, the precipitation occurs from a still strongly basic medium 
which implies a possible recycling of the $\mathrm{NaOH}$ solution [21]. The second goal of this study is to explore the feasibility of using the recovered boehmite powder as a solid adsorbent for the treatment of oilfield PW collected from an oilfield in east Egypt. To the best of authors' knowledge, this will be the first work reported in using boehmite powder recovered from waste for the treatment of oilfield PW which represents the main novelty of our present work. Boehmite is always appears as a transient or intermediate compound which is calcined to produce alumina. Compared to alumina and other solid oxides that can be used as adsorbents, boehmite is characterized by a simple energy-saving preparation method that involves only drying at $100{ }^{\circ} \mathrm{C}$ which can be replaced by drying under sunlight for few days especially if the process will be scaled up. As a general primary test, the efficiency of the prepared boehmite in the reduction of a number of pollution indicators (PIs) including turbidity, sulfides, sulfates, TOC, TPH, and COD was first investigated by comparing the values of these indicators before and after the treatment of PW with boehmite adsorbent. Then, the effect of the adsorbent dose, treatment time, and $\mathrm{pH}$ of the media on the adsorption efficiency was examined using chemical oxygen demand as pollution indicator. The COD was chosen as it represents a pollution indicator which describes the organic matter content in the water and can be defined as the number of oxygen equivalents consumed in the oxidation of organic compounds polluting wastewater [24]. Commercial activated carbon, as the most effective solid adsorbent, was used as a reference adsorbent for all the adsorption experiment carried out in this study.

\section{Experimental}

\section{Preparation of boehmite powder from aluminum cans waste}

Clean aluminum cans waste ( $40 \mathrm{~g})$ were cut to small pieces and immersed in $1000 \mathrm{ml}$ of $2 \mathrm{M} \mathrm{NaOH}$ solution. The mixture was stirred until all the aluminum pieces are completely dissolved to produce sodium aluminate solution. Then, the produced sodium aluminate solution was filtered to remove any impurities such as plastic coatings. $\mathrm{H}_{2} \mathrm{O}_{2}(30 \%)$ solution was added drop by drop to the sodium aluminate solution with continuous stirring until a white precipitate (boehmite) is formed. The produced boehmite precipitate was filtered and washed several times with distilled water and then, dried at $100{ }^{\circ} \mathrm{C}$ for $24 \mathrm{~h}$.

\section{Characterization of the solid adsorbent samples}

X-ray powder diffraction analysis (XRD) of the samples was carried out using an X-ray diffractometer (Rigaku
RU-200A) operated at $40 \mathrm{kV}$ and $30 \mathrm{~mA}$ with $\mathrm{CuK} \alpha$ radiation using monochromator. TG and DSC analysis were performed at a heating rate of $15{ }^{\circ} \mathrm{C} / \mathrm{min}$ in a flow of $40 \mathrm{~cm}^{3} / \mathrm{min}$ dry nitrogen, using automatically recording model $50 \mathrm{H}$ Shimadzu thermal analyzer, Japan. The thermal analyzer is equipped with a data acquisition and handling system (TA-50WSI). Highly sintered $\alpha-\mathrm{Al}_{2} \mathrm{O}_{3}$ was used as the reference material in DSC measurements, while temperature and enthalpy readings were calibrated versus the melting point $\left(157^{\circ} \mathrm{C}\right)$ and the heat of fusion $\left(\Delta H_{\mathrm{f}}=28.24 \mathrm{~J} / \mathrm{g}\right.$ ) of Specpure Indium metal (a Johnson Matthey product), respectively [25]. Transmission electron microscope (TEM) was used to analyze the morphology of the samples using Philips TECNAI F20 Transmission electron microscope at $200 \mathrm{kV}$. The samples were stirred by ultrasonic about $2 \mathrm{~min}$ in ethanol, and then, the copper grids were dipped in the suspension and evaporated underneath the infrared light before observation. Isothermal $\mathrm{N}_{2}$ adsorption-desorption measurements were carried out at liquid nitrogen temperature $\left(-195^{\circ} \mathrm{C}\right)$, using an automatic ASAP 2010 Micromeritics sorptometer (USA) equipped with an outgassing platform and an online data acquisition and handling system operating BET, $t$ and BJH analytical software for the adsorption-desorption data. The adsorptive $\mathrm{N}_{2}$ gas was a $99.2 \%$ pure product of Egyptian Sugar and Integrated Industries (El-Hawamdia, Egypt). Small portions of adsorbents $(\sim 100 \mathrm{mg})$ were outgassed at $200{ }^{\circ} \mathrm{C}$ and $10^{-5}$ Torr for $2 \mathrm{~h}$, prior to exposure to the adsorptive atmosphere. Data determined by the adsorption branch of the isotherm were BET analyzed for the monolayer capacity, $V_{\mathrm{m}}\left[\mathrm{cm}^{3}(\mathrm{STP}) / \mathrm{g}\right]$, specific surface area, $S_{\mathrm{BET}}\left(\mathrm{m}^{2} / \mathrm{g}\right)$, and the BET constant, $C_{\mathrm{BET}}$. The standard $t$ curve data were used to analyze the observed adsorption data for the pore structure, whereas the BJH method was applied to analyze the desorption data for the pore volume distribution calculations.

\section{Adsorption process}

The adsorption process was investigated through a batch process using a specified dosage of adsorbent in $100 \mathrm{ml}$ of PW of known initial values of pollution indicators (i.e. turbidity, sulfides, sulfates, TOC, TPH, and COD). The water-adsorbent mixture was placed in a mechanical shaker and agitated at $100 \mathrm{rpm}$ for a specified contact time. After the adsorption process, the mixture was filtered and the values of pollution indicators of the filtrate were measured. Under all the adsorption conditions studied here, the values of pollution indicators of PW was measured before and after the adsorption process and then, \% reduction of pollution indicator (\% PI reduction) was calculated as follow: 
$\% \mathrm{PI}$ reduction $=\frac{\mathrm{PI}_{(0)}-\mathrm{PI}_{(t)}}{\mathrm{PI}_{(0)}} \times 100$.

where $\mathrm{PI}_{(0)}$ is the value of pollution indicator before starting the adsorption process, and $\mathrm{PI}_{(\mathrm{t})}$ is the value of pollution indicator after the contact with adsorbent for time $t$. The standard procedures of APHA 2130, APHA 4500-S, APHA$\mathrm{SO}_{4}$, APHA 5310, APHA 5520 and APHA 5220 were followed to determine turbidity, sulfides, sulfates, TOC, TPH and COD, respectively.

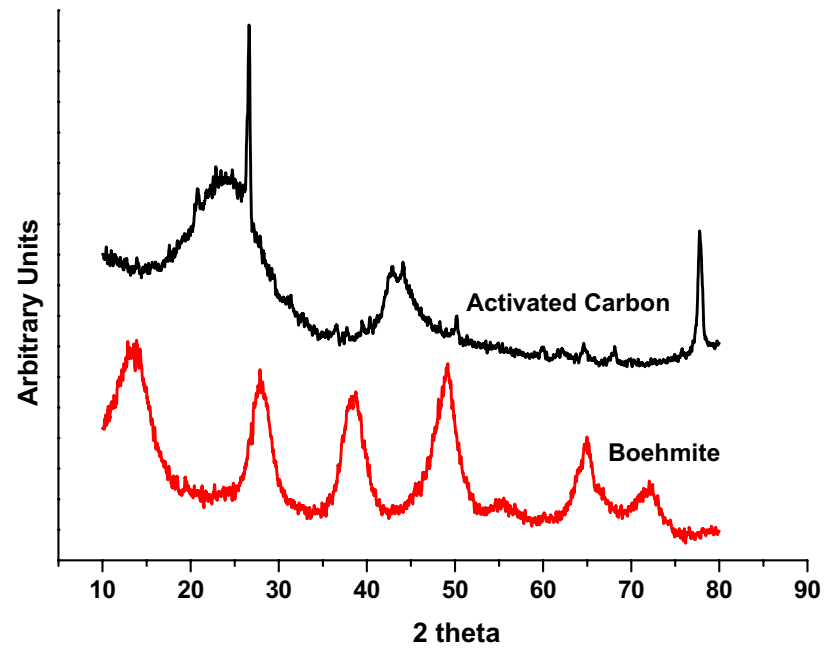

Fig. 1 XRD patterns of boehmite and commercial activated carbon

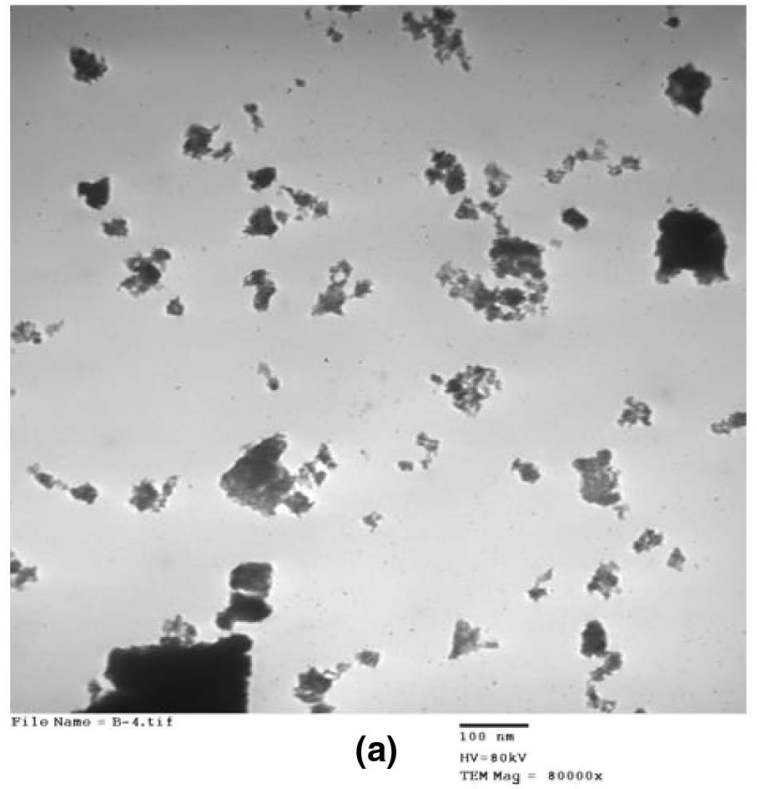

Fig. 2 TEM images of boehmite (a) and commercial activated carbon (b)

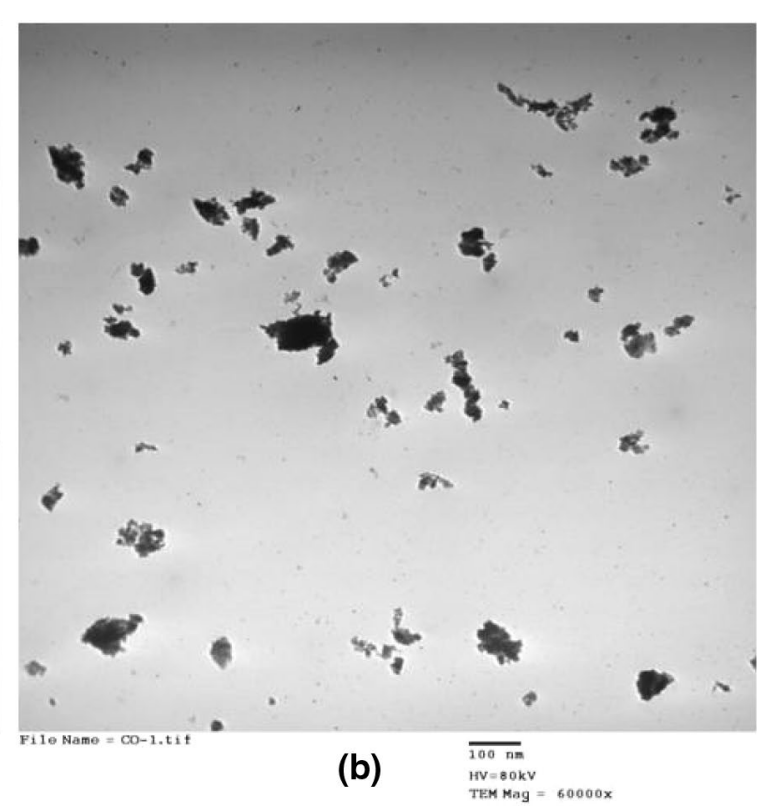

\section{Results and discussion}

\section{Catalyst characterization}

Figure 1 displays the XRD patterns of boehmite powder and commercial activated carbon. The diffractogram of boehmite exhibit typical diffraction peaks indexed to boehmite phase $\mathrm{AlO}(\mathrm{OH})$ (JCPDS 00-049-0133) with a relatively broad peaks that indicate a poor crystalinity of the prepared boehmite sample. There are no diffraction peaks ascribing to other boehmite phases indicating a high purity of the prepared sample. The diffractogram of commercial activated carbon exhibit diffraction peaks corresponds to carbon (JCPDS 00-054-0501) [26-28]. Figure 2 shows the TEM images of boehmite and commercial activated carbon. The two images of boehmite and carbon shows aggregates composed of a non-uniform spheres which come in accordance with the relative amorphous nature appeared in the XRD spectrum. By comparing the size of spheres in Fig. 2 with the scale bar $(100 \mathrm{~nm})$, we can clearly see that the particle sizes for both boehmite and carbon are in the nano-scale. The pore size distribution curves of boehmite and commercial activated carbon are shown in Fig. 3 and the textural data by BET, $t$ and BJH analysis of the $\mathrm{N}_{2}$ adsorption results over the two samples are shown in Table 1. Pore size distribution shown in Fig. 3 indicates that both of boehmite and carbon are mesoporous $(4 \mathrm{~nm}<$ size $<100 \mathrm{~nm})$ [29] and have relatively the same mean pore diameter and the same distribution of pore size. From Table 1, we can see that the total surface area of boehmite $\left(287.5 \mathrm{~m}^{2} \mathrm{~g}^{-1}\right)$ 


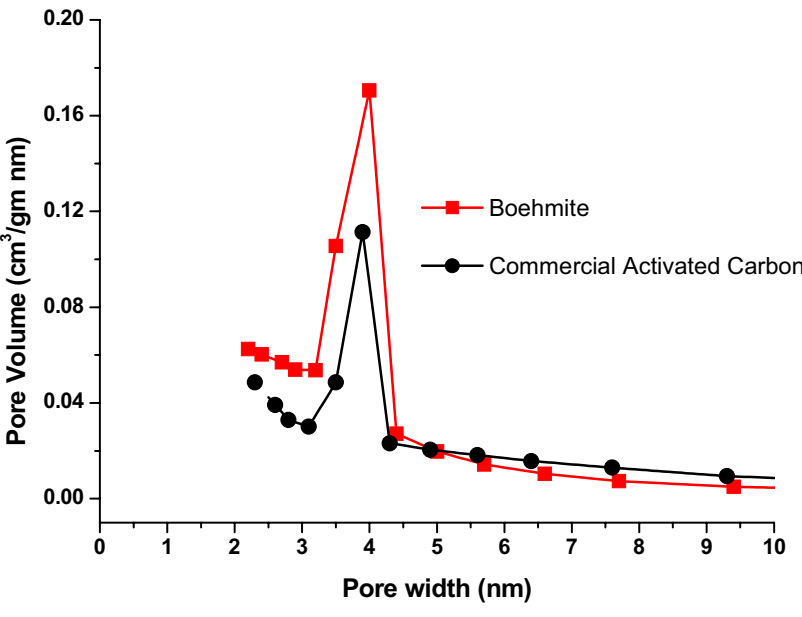

Fig. 3 Pore size distribution of boehmite and commercial activated carbon

is much smaller than that of commercial activated carbon $\left(759.2 \mathrm{~m}^{2} \mathrm{~g}^{-1}\right)$. Even though, the external surface area of boehmite $\left(266.8 \mathrm{~m}^{2} \mathrm{~g}^{-1}\right)$ is relatively similar to that of activated carbon $\left(277.9 \mathrm{~m}^{2} \mathrm{~g}^{-1}\right)$. This is due to the high micropore surface area in the case of commercial activated carbon $\left(481.3 \mathrm{~m}^{2} \mathrm{~g}^{-1}\right)$ which is about $63.4 \%$ of its total surface area compared to that in the case of boehmite $\left(20.7 \mathrm{~m}^{2} \mathrm{~g}^{-1}\right)$ which is only $7.2 \%$ of its total surface area. The prepared boehmite powder was subjected to TG and DSC analysis in a dynamic nitrogen atmosphere to investigate its thermal behavior. Figure 4 shows the DSC-TG curves of the boehmite powder. The TG curve shows two mass loss steps with a total mass loss of $25 \%$ which have two corresponding DSC endothermic peaks. The first step centered at $100{ }^{\circ} \mathrm{C}$ and associated with $6.5 \%$ mass loss is likely corresponds to the dehydration process due to the desorption of loosely bound or physisorbed water molecules [21]. The second step centered at $375{ }^{\circ} \mathrm{C}$ and associated with $18.5 \%$ mass loss can be attributed to the dehydroxylation of boehmite during the conversion of boehmite to alumina [21]:

$2 \mathrm{AlO}(\mathrm{OH}) \rightarrow \mathrm{Al}_{2} \mathrm{O}_{3}+\mathrm{H}_{2} \mathrm{O}$.

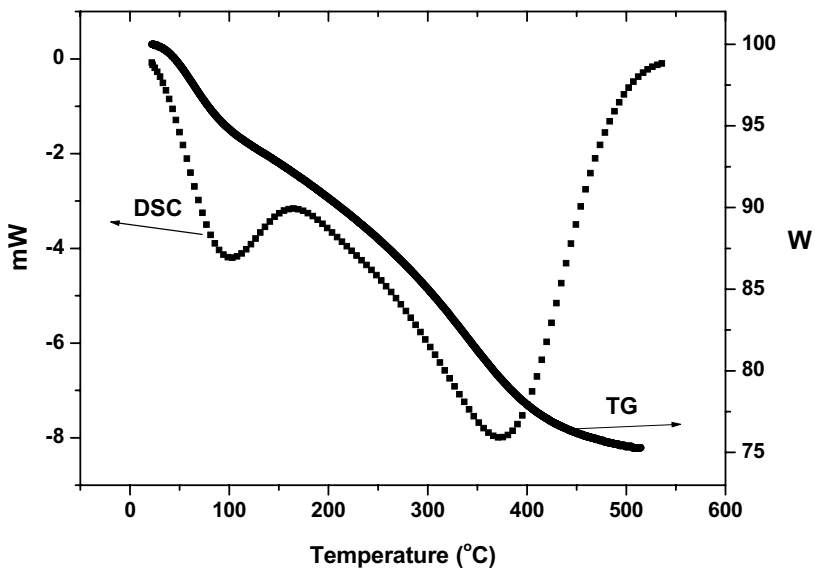

Fig. 4 TG and DSC curves of boehmite powder

\section{Adsorption process}

Table 2 shows the physico-chemical properties of the produced water collected from an oilfield in east Egypt. It is evident that the produced water was polluted with organic and inorganic loads which are reflected in the values of pollution indicators included in the table. For example, the COD concentration, $1150 \mathrm{mg} / \mathrm{l}$, in the produced water is higher than that of the permissible limit [100-200 $\mathrm{mg} / \mathrm{l}]$ for irrigation and horticultural uses [30]. Figure 5 shows the efficiency of the prepared boehmite compared to commercial activated carbon in the treatment of produced water as indicated by the values of $\%$ reduction of six different pollution indicators, i.e. turbidity, sulfides, sulfates, TOC, TPH and COD (adsorbent dosage: $30 \mathrm{~g} / \mathrm{L}, \mathrm{pH}: 7.0$ and contact time: $24 \mathrm{~h}$ ). It is clear from Fig. 5 that boehmite has a selectivity and removal power relatively similar to that of commercial activated carbon towards the monitored pollution indicators. There are different parameters that can affect the adsorption efficiency of solid adsorbents such as temperature, contact time, $\mathrm{pH}$, adsorbent dosage, etc. Herein, the effect of contact time, $\mathrm{pH}$, and adsorbent dosage on the adsorption efficiency of
Table 1 BET, $t$ and BJH analysis results of $\mathrm{N} 2$ adsorption data determined on boehmite and commercial activated carbon

\begin{tabular}{|c|c|c|c|c|c|c|c|c|c|}
\hline \multirow[t]{2}{*}{ Sample } & \multicolumn{2}{|l|}{ BET } & \multicolumn{2}{|l|}{$t$} & \multicolumn{5}{|l|}{ BJH } \\
\hline & $\begin{array}{l}S_{\mathrm{BET}} \\
\mathrm{m}^{2} \mathrm{~g}^{-1}\end{array}$ & $C_{\mathrm{BET}}$ & $\begin{array}{l}S_{\text {ext }} \\
\mathrm{m}^{2} \mathrm{~g}^{-1}\end{array}$ & $\begin{array}{l}S_{\mathrm{MP}} \\
\mathrm{m}^{2} \mathrm{~g}^{-1}\end{array}$ & $\begin{array}{l}S_{\text {cum }} \\
\mathrm{m}^{2} \mathrm{~g}^{-1}\end{array}$ & $\begin{array}{l}\text { APD } \\
\mathrm{nm}\end{array}$ & $\begin{array}{l}\text { MPD } \\
\mathrm{nm}\end{array}$ & $\begin{array}{l}V_{\text {cum }} \\
\mathrm{cm}^{3} \mathrm{~g}^{-1}\end{array}$ & $\begin{array}{l}V_{\mathrm{t}} \\
\mathrm{cm}^{3} \mathrm{~g}^{-1}\end{array}$ \\
\hline Boehmite & 287.5 & 112.5 & 266.8 & 20.7 & 279.4 & 5.1 & 3.9 & 0.356 & 0.298 \\
\hline Activated carbon & 759.2 & 128.5 & 277.9 & 481.3 & 230.3 & 5.8 & 4.0 & 0.33 & 0.53 \\
\hline
\end{tabular}

$S_{B E T}$ BET surface area, $C_{B E T}$ BET C constant, $S_{\text {ext }}$ external surface area, $S_{M P}$ micropore surface area; $S_{\text {cum }}$ cumulative surface area of pores, $A P D$ average pore diameter, $M P D$ mean pore diameter, $V_{\text {cum }}$ cumulative pore volume, $V_{t}$ total pore volume 
Table 2 Characteristics of produced water

\begin{tabular}{lll}
\hline Parameter & Unit & Value \\
\hline $\mathrm{pH}$ & - & 7.31 \\
Conductivity & $\mathrm{mho} / \mathrm{cm}$ & $1.095 \times 10^{-2}$ \\
Turbidity & $\mathrm{NTU}$ & 30.3 \\
Total organic carbon & $\mathrm{mg} / \mathrm{l}$ & 310 \\
Salinity & $\mathrm{mg} / \mathrm{l}$ & 4504.5 \\
Hardness & $\mathrm{mg} / \mathrm{l}$ & 4799.3 \\
Total dissolved solids & $\mathrm{mg} / \mathrm{l}$ & $10,131.0$ \\
Chemical oxygen demand & $\mathrm{mg} / \mathrm{l}$ & 1150 \\
Total petroleum hydrocarbon & $\mathrm{mg} / 1$ & 711 \\
Sodium & $\mathrm{mg} / \mathrm{l}$ & 1121.0 \\
Potassium & $\mathrm{mg} / \mathrm{l}$ & 577.95 \\
Magnesium & $\mathrm{mg} / \mathrm{l}$ & 705.50 \\
Calcium & $\mathrm{mg} / \mathrm{l}$ & 758.52 \\
Iron & $\mathrm{mg} / \mathrm{l}$ & 0.50 \\
Strontium & $\mathrm{mg} / \mathrm{l}$ & 8.99 \\
Barium & $\mathrm{mg} / \mathrm{l}$ & 0.62 \\
Fluoride & $\mathrm{mg} / \mathrm{l}$ & 22.7 \\
Chloride & $\mathrm{mg} / \mathrm{l}$ & 2730 \\
Bicarbonate & $\mathrm{mg} / \mathrm{l}$ & 902 \\
Sulfate & $\mathrm{mg} / \mathrm{l}$ & 3173 \\
\hline & & \\
\hline
\end{tabular}

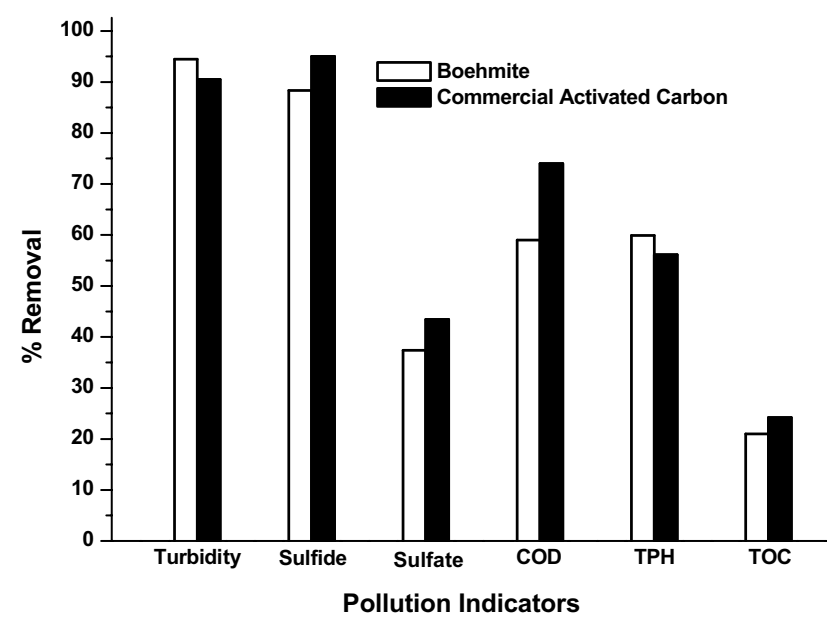

Fig. 5 The efficiency (\% removal) of the prepared boehmite and commercial activated carbon in the treatment of produced water (adsorbent dosage: $30 \mathrm{~g} / \mathrm{L}, \mathrm{pH}$ : 7.0 and contact time: $24 \mathrm{~h}$ ). The initial values of pollution indicators are indicated in Table 2

both of boehmite and commercial activated carbon at room temperature was investigated using $\mathrm{COD}$ of $\mathrm{PW}$ as indicator.

Figure 6a shows the \%COD reduction in produced water as a function of contact time with the adsorbents (boehmite and activated carbon). This test was carried out to determine the equilibrium time for maximum adsorbent uptake. The contact time was varied from 6 to $36 \mathrm{~h}$ using produced water with initial COD of $1150 \mathrm{mg} / \mathrm{L}$ and with adsorbent dosage
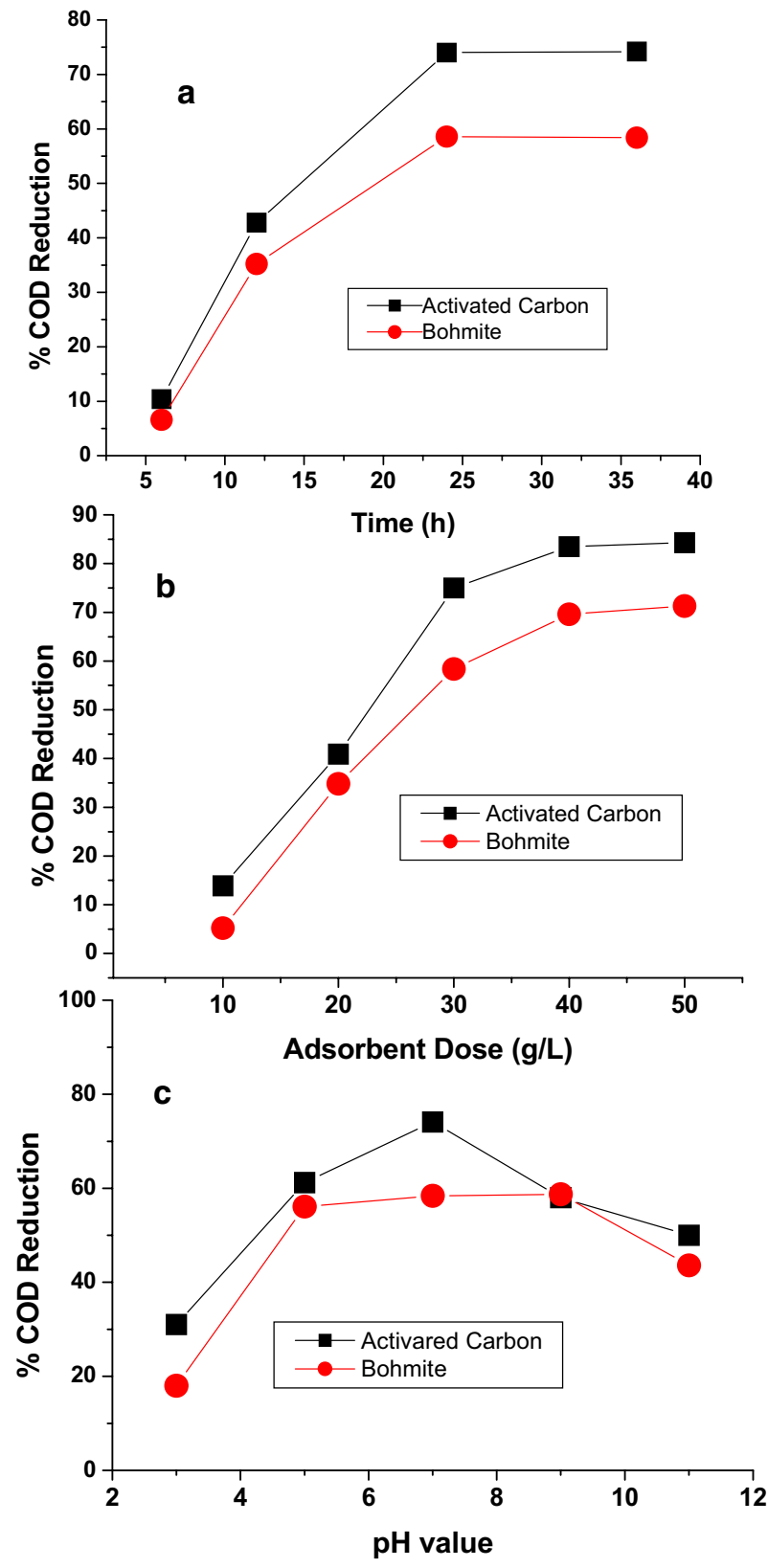

Fig. 6 Effect of the contact time (a), adsorbent dosage, (b) and solution $\mathrm{pH}(\mathbf{c})$ on \% COD reduction by boehmite and commercial activated carbon

of $30 \mathrm{~g} / \mathrm{L}$ at $\mathrm{pH}$ value of 7.0. From Fig. 6a we can see that the COD removal increased by increasing the contact time and the equilibrium is reached after $24 \mathrm{~h}$ with $58.6 \%$ and $74 \%$ COD reduction for boehmite and carbon, respectively. It is clear from Fig. 6a that the reasonable time for reaching adsorption equilibrium is $24 \mathrm{~h}$ after which the removal efficiency is relatively stable with both of boehmite and carbon. Thus for all the next adsorption studies, the equilibration period was kept at $24 \mathrm{~h}$. Figure $6 \mathrm{~b}$ shows the percentage COD reduction in produced water as a function of 
adsorbent dosage (i.e. 10, 20, 30, 40 and $50 \mathrm{~g} / \mathrm{L}$ ). $100 \mathrm{ml}$ of produced water was used with initial COD concentration of $1150 \mathrm{mg} / \mathrm{L}, \mathrm{pH}$ value of 7.0 and contact time of $24 \mathrm{~h}$. As shown in Fig. 6b, the COD reduction efficiency increased by increasing the adsorbent dosage to reach the equilibrium adsorption capacity at $40 \% \mathrm{~g} / \mathrm{L}$ adsorbent dosage for both boehmite and activated carbon. At the $40 \% \mathrm{~g} / \mathrm{L}$ dosage, the COD reduction capacity is $69.6 \%$ for boehmite and $83.5 \%$ for activated carbon, and by increasing the dosage to $50 \mathrm{~g} / \mathrm{L}$, the efficiency is relatively stable for the two adsorbents. The increase in the COD reduction efficiency with increasing the adsorbent dosage can be attributed to the increase in the number of active sites at which the adsorption takes place. For the next adsorption study, the adsorbent dosage was kept at $40 \% \mathrm{~g} / \mathrm{L}$. Figure $6 \mathrm{c}$ shows the effect of initial $\mathrm{pH}$ value of produced water on the COD removal efficiency of the solid adsorbent (boehmite and activated carbon). $100 \mathrm{ml}$ of produced water was used with initial COD concentration of $1150 \mathrm{mg} / \mathrm{L}$, adsorbent dosage of $40 \mathrm{~g} / \mathrm{L}$ and contact time of $24 \mathrm{~h}$. From Fig. $6 \mathrm{c}$ we can conclude that the COD removal efficiency of boehmite is the best in the $\mathrm{pH}$ range (5-9) and at higher or lower $\mathrm{pH}$ values, the adsorption efficiency decreases. The activated carbon has better efficiency at $\mathrm{pH}=7$ and then, its $\mathrm{COD}$ reduction efficiency decreased gradually by increasing or decreasing the $\mathrm{pH}$ value. The decrease in the COD reduction efficiency of both boehmite and activated carbon at higher and lower $\mathrm{pH}$ values is likely due to the presence of $\mathrm{H}^{+}$and $\mathrm{OH}^{-}$ions in relatively higher concentrations. These species (i.e. $\mathrm{H}^{+}$and $\mathrm{OH}^{-}$ions) with a relatively low mass have higher mobility in solution than those of the COD causing complex organic molecules and will compete with these organic molecules to occupy the adsorption sites [30].

We can see clearly from the results in Fig. 6 that the COD reduction efficiency of boehmite is about $85 \%$ that of commercial activated carbon at adsorbent dose of $40 \mathrm{~g} / \mathrm{l}$, even though the total surface area of activated carbon is about
2.5 times that of boehmite (see Table 2). This may indicate a high density of surface adsorption sites over the prepared boehmite compared to commercial carbon. In addition, this carbon-like activity of the prepared boehmite can be related also to the porosity and the total and external surface area over the two adsorbents. Even though the higher total surface area of carbon; the external surface areas of the two adsorbents are relatively similar and the two adsorbents are characterized by narrow pore diameter $(\approx 4 \mathrm{~nm}$, see Fig. 4$)$. So that, if the adsorption process over the two adsorbents takes place mainly on the external surface area, this will give another reason for the similar adsorption power of the two adsorbents. These result shows that the boehmite recovered from aluminum cans waste can be considered as a good candidate as a cheap and available carbon-like adsorbent for the treatment of oilfield produced water. The maximum COD removal power of boehmite was compared with some other adsorbents reported in the literature and the values are given in Table 3 [30-34]. From Table 3, it is clear that the COD removal power of boehmite is comparable with other adsorbents which indicate that boehmite is an effective adsorbent for the treatment of oil-contaminated wastewater.

\section{Adsorption isotherm study}

Adsorption isotherm is a graph between the amount of adsorbate adsorbed on the surface of adsorbent and the pressure or concentration of the adsorbent at constant temperature. Adsorption isotherms gives important information about the adsorption process including adsorption behavior, heat of adsorption, affinity of the adsorbate to the adsorbent, homogeneity/heterogeneity of the adsorbent surface, etc. [35]. Depending on the arrangement of the isotherm equation, the adsorption isotherms for the different models can be presented using a linear or non-linear regression method. Then, the correlation coefficient $\left(R^{2}\right)$ and/or error analysis can be used to evaluate the applicability of the used isotherm

Table 3 Comparison of COD removal efficiency of boehmite with other adsorbents

\begin{tabular}{|c|c|c|c|c|}
\hline Adsorbent & $\begin{array}{l}\text { Adsorbent dose } \\
(\mathrm{g} / \mathrm{l})\end{array}$ & $\begin{array}{l}\text { Initial COD value } \\
(\mathrm{mg} / \mathrm{l})\end{array}$ & $\%$ COD removal & References \\
\hline Boehmite & 40 & 1150 & 69.6 & This study \\
\hline Commercial activated carbon & 40 & 1150 & 83.5 & This study \\
\hline Fly ash & 60 & 1080 & 87.84 & {$[30]$} \\
\hline Brick kiln ash & 45 & 1080 & 83.22 & {$[30]$} \\
\hline Activated carbon & 40 & 1080 & 99.35 & {$[30]$} \\
\hline Polyethylene glycol functionalized carbon nanotubes & 0.2 & 1094 & 99.68 & {$[31]$} \\
\hline Chitosan-coated bentonite & 27 & 1348 & 73.34 & {$[32]$} \\
\hline Cow dung ash & 20 & 2600 & 66 & {$[33]$} \\
\hline Activated cow dung ash & 20 & 2600 & 79 & {$[33]$} \\
\hline Activated carbon from local cypress cones & 2 & 865 & 19 & [34] \\
\hline
\end{tabular}



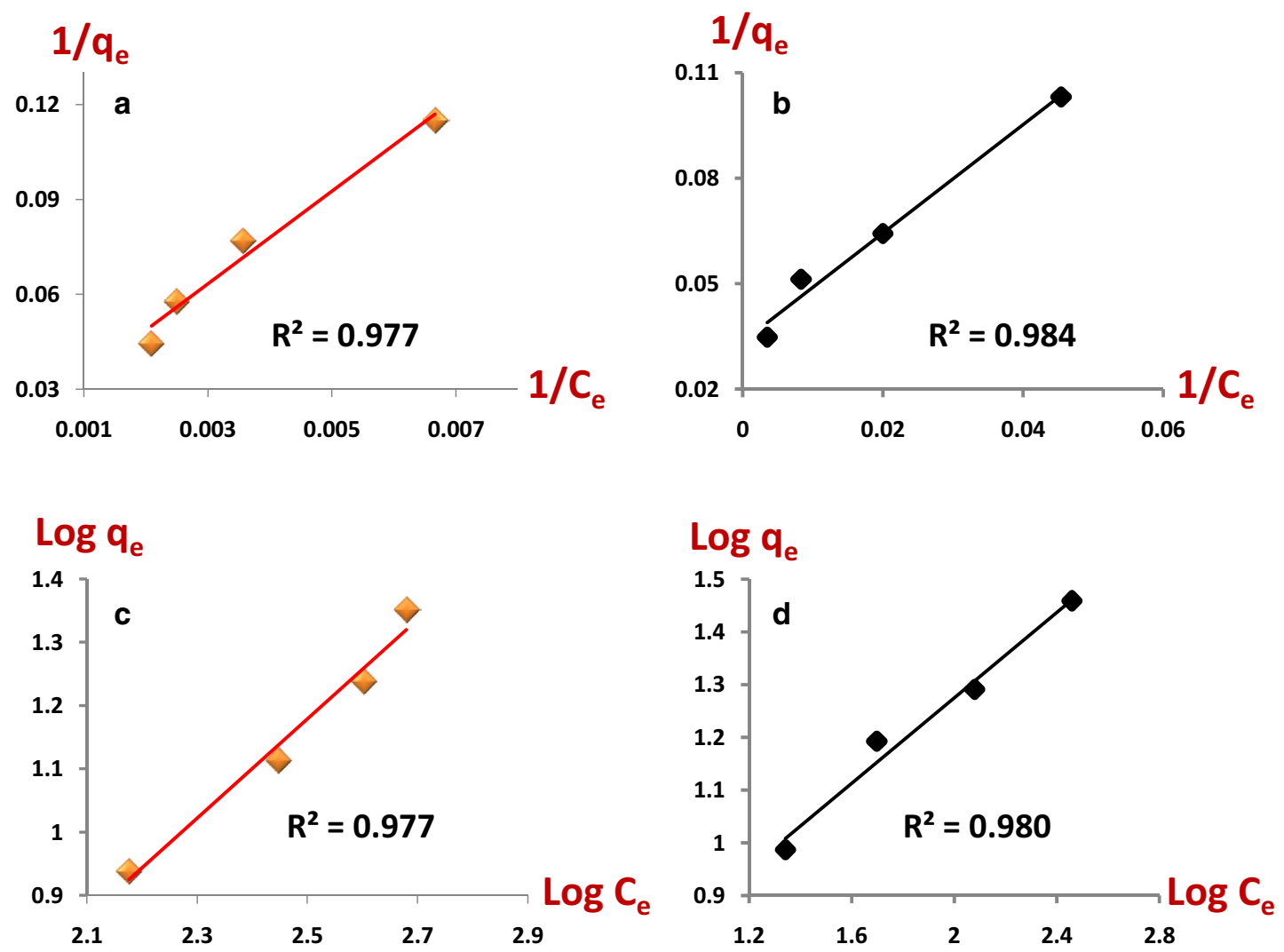

Fig. 7 Linearized adsorption isotherms; Langmuir isotherm of boehmite (a), Langmuir isotherm of carbon (b), Freundlich isotherm of boehmite (c) and Freundlich isotherm of carbon (d)

models [35-37]. Several adsorption isotherms can be used for the single-component systems while the isotherms used for multi-component systems (such as produced water) are those based on Langmuir and Freundlich isotherms [35]. Langmuir model assumes that the adsorption occurs only at a specific site over a homogenous adsorbent surface to form a monolayer of the adsorbate while Freundlich model assumes that the adsorption occurs on the adsorbent's heterogeneous surface to form monolayer or multilayer of adsorbate molecules [35-37].The Langmuir model (1916) can be represented by the following linear equation [35]:

$\frac{1}{q_{\mathrm{e}}}=\frac{1}{q_{\mathrm{m}}}+\frac{1}{q_{\mathrm{m}} k_{\mathrm{L}} C_{\mathrm{e}}}$,

where, $C_{\mathrm{e}}$ is the concentration of the adsorbate in the solution at equilibrium $(\mathrm{mg} / \mathrm{L}), q_{\mathrm{e}}$ is the amount of adsorbate adsorbed by unit weight of the adsorbent at equilibrium $(\mathrm{mg} / \mathrm{g}), q_{\max }$ is the maximum adsorption capacity of the adsorbate by the adsorbent $(\mathrm{mg} / \mathrm{g})$ and $K_{\mathrm{L}}$ is the Langmuir constant which is related to the free energy of adsorption and can be taken as a measure of the binding energy of adsorbate to adsorbent. By plotting $1 / q_{\mathrm{e}}$ as a function of $1 / C_{\mathrm{e}}$, the slope and the intercept of the obtained line can be used to calculate the values of $K_{\mathrm{L}}$ and $q_{\max }$ to characterize the adsorption process. The Freundlich model (1926) can be represented by the following linear equation $[38,39]$ :

$\log q_{\mathrm{e}}=\log K_{\mathrm{f}}+(1 / n) \log C_{\mathrm{e}}$,

where $K_{\mathrm{f}}$ and $n$ are the Freundlich constants that are related to capacity of adsorption and intensity of adsorption, respectively. By plotting $\log q_{\mathrm{e}}$ as a function of $\log C_{\mathrm{e}}$, the values of $n$ and $K_{\mathrm{f}}$ can be obtained from the slope and the intercept, respectively.

To find the suitable model that describe the adsorption process by boehmite and activated carbon, the Langmuir and Freundlich models were applied to the obtained experimental results. Figure 7a, b shows the linearized Langmuir isotherm plots at room temperature for boehmite and activated carbon, respectively. Figure $7 \mathrm{c}, \mathrm{d}$ shows the linearized Freundlich isotherm plots at room temperature for boehmite and activated carbon, respectively. Table 4 shows the Langmuir and Freundlich isotherm parameters for COD adsorption onto boehmite and activated carbon. From the values of the correlation coefficient $\left(R^{2}\right)$ we can conclude that both 
Table 4 Langmuir and Freundlich isotherm parameters for COD adsorption onto boehmite and commercial activated carbon

\begin{tabular}{lllllllll}
\hline Adsorbent & \multicolumn{2}{l}{ Langmuir model } & & \multicolumn{3}{l}{ Freundlich model } \\
\cline { 2 - 3 } & $K_{\mathrm{L}}(\mathrm{L} / \mathrm{mg})$ & $q_{\mathrm{m}}(\mathrm{mg} / \mathrm{g})$ & & $R^{2}$ & & $n$ & $K_{\mathrm{f}}$ & $R^{2}$ \\
\hline Boehmite & 0.0013 & 52.6 & 0.977 & & 1.3 & 0.17 & 0.977 \\
Activated carbon & 0.0214 & 30.3 & 0.984 & & 2.5 & 2.9 & 0.980 \\
\hline
\end{tabular}

Langmuir and Freundlich models are suitable to describe the adsorption process in the case of boehmite and commercial activated carbon. This indicates the existents of both monolayer and multilayer adsorption on the surfaces of boehmite and activated carbon during the adsorption process for the reduction of COD. This is probably due to the nature of produced water as a multi-component system in which the adsorbate is a large number of different components with different properties. Ying He and his co-workers [37] reported the co-existence of monolayer and multilayer adsorption during the study of COD removal from leachate containing about 27 different pollutants using activated carbon as adsorbent. The values of the Freundlich constant (n) for boehmite and activated carbon are higher than 1 and less than 10 which indicate that the adsorption process is favorable in both cases [40-43].

\section{Conclusion}

High surface area boehmite nanopowder was recovered from aluminum can waste by dissolving the cans in $\mathrm{NaOH}$ solution followed by addition of $\mathrm{H}_{2} \mathrm{O}_{2}$ solution. The feasibility of the prepared boehmite powder as a new low-cost adsorbent for the treatment of the oilfield produced water was investigated. The effect of the adsorbent dose, treatment time, and $\mathrm{pH}$ of the media on the COD reduction from the produced water was studied. The application of Langmuir and Freundlich models to the experimental results indicated the coexistence of monolayer and multilayer adsorption of oil pollutants on the surfaces of boehmite. The study demonstrated that boehmite powder recovered from aluminum cans waste can be considered as a promising low-cost carbon-like adsorbent for the partial treatment of produced water.

Open Access This article is licensed under a Creative Commons Attribution 4.0 International License, which permits use, sharing, adaptation, distribution and reproduction in any medium or format, as long as you give appropriate credit to the original author(s) and the source, provide a link to the Creative Commons licence, and indicate if changes were made. The images or other third party material in this article are included in the article's Creative Commons licence, unless indicated otherwise in a credit line to the material. If material is not included in the article's Creative Commons licence and your intended use is not permitted by statutory regulation or exceeds the permitted use, you will need to obtain permission directly from the copyright holder. To view a copy of this licence, visit http://creativecommons.org/licenses/by/4.0/.

\section{References}

1. Al-Ghouti MA, Khan M, Nasser MS, Al-Saad K, Ee Heng O (2021) Recent advances and applications of municipal solid wastes bottom and fly ashes: insights into sustainable management and conservation of resources. Environ Technol Innov 21:101267

2. Golwala H, Zhang X, Iskander SM, Smith AL (2021) Solid waste: an overlooked source of microplastics to the environment. Sci Total Environ 769:144581

3. How LF, Islam A, Jaafar MS, Taufiq-Yap YH (2017) Extraction and characterization of $\gamma$-alumina from waste aluminium dross. Waste Biomass Valor 8:321-327

4. Yoo SJ, Yoon HS, Jang HD, Hong ST, Park HS, Park SU, Kwak DH, Lee SI (2007) Synthesis of aluminum ethoxide from used aluminum cans. Korean J Chem Eng 24(5):872-876

5. Abdelkader A, Osman AI, Halawy SA, Mohamed MA (2018) Preparation and characterization of mesoporous $\gamma$-A12O 3 recovered from aluminum cans waste and its use in the dehydration of methanol to dimethyl ether. J Mater Cycles Waste Manag 20:1428-1436

6. Li Y, Dong H, Li L, Tang L, Tian R, Li R, Chen J, Xie Q, Jin Z, Xiao J, Xiao S, Zeng G (2021) Recent advances in waste water treatment through transition metal sulfides-based advanced oxidation processes. Water Res 192:116850

7. Ahmadun F-R, Pendashteh A, Abdullah LC, Biak DRA, Madaeni SS, Abidin ZZ (2009) Review of technologies for oil and gas produced water treatment. J Hazard Mater 170:530-551

8. Gargouri B, Gargouri OD, Gargouri B, Trabelsi SK, Abdelhedi R, Bouaziz M (2014) Application of electrochemical technology for removing petroleum hydrocarbons from produced water using lead dioxide and boron-doped diamond electrodes. Chemosphere 117:309-315

9. Abd Halim NS, Wirzal MDH, Hizam SM, Bilad MR, Nordin NAHM, Sambudi NS, Putra ZA, Yusoff AM (2021) Recent development on electrospun nanofier membrane for produced water treatment: a review. J Environ Chem Eng 9:104613

10. Li G, An T, Chen J, Sheng G, Fu J, Chen F, Zhang S, Zhao H (2006) Photoelectrocatalytic decontamination of oilfield produced wastewater containing refractory organic pollutants in the presence of high concentration of chloride ions. J Hazard Mater B 138:392-400

11. Santos EV, Rocha JHB, Araújo DM, Moura DC, Martínez-Huitle CA (2014) Decontamination of produced water containing petroleum hydrocarbons by electrochemical methods: a minireview. Environ Sci Pollut Res 21:8432-8441

12. Ersahin ME, Ozgun H, Kaya R, Mutlu BK, Kinaci C, Koyuncu I (2018) Treatment of produced water originated from oil and gas production wells: a pilot study and cost analysis. Environ Sci Pollut Res Int 25:6398-6406

13. Ali N, Bilal M, Khan A, Ali F, Yang Y, Khan M, Adil SF, Iqbal HMN (2020) Dynamics of oil-water interface demulsi fi cation using multifunctional magnetic hybrid and assembly materials. J Mol Liq 312:113434

14. Ali N, Bilal M, Khan A, Ali F, Khan H, Khan HA, Rasool K, Iqbal HMN (2020) Understanding the hierarchical assemblies and oil/water separation applications of metal-organic frameworks. J Mol Liq 318:114273

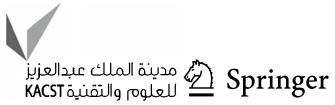


15. Ali N, Bilal M, Khan A, Ali F, Iqbal HMN (2020) Design, engineering and analytical perspectives of membrane materials with smart surfaces for efficient oil/water separation. Trends Anal Chem 127:115902

16. Al Haddabi M, Vuthaluru H, Znad H, Ahmed M (2015) Removal of dissolved organic carbon from oily produced water by adsorption onto date seeds: equilibrium, kinetic, and thermodynamic studies. Water Air Soil Pollut 226:172

17. Jiao WQ, Liang XM, Wang YM, He M-Y (2014) Formation of hierarchical boehmite with different nanostructures in dry-gel conversion process. CrystEngComm 16:3348-3358

18. Pardo P, Calatayud JM, Alarcón J (2014) Improvement of boehmite nanoparticles' aqueous dispersability by controlling their size, shape and crystalinity. RSC Adv 4:48389-48398

19. Zanganeh N, Zanganeh S, Rajabi A, Allahkarami M, Ghahnavyeh RR, Moghaddas A, Aieneravaie M, Asadizanjani N, Sadrnezhaad SK (2014) Flower-like boehmite nanostructure formation in twosteps. J Coord Chem 67:555-562

20. Li G, Sun Y, Li X, Liu Y (2016) Adsorption of Congo red from water with spindlelike boehmite: the role of lattice plane (020). RSC Adv 6:11855-11862

21. El-Katatny EA, Halawy SA, Mohamed MA, Zaki MI (1998) A novel synthesis of high-area alumina via $\mathrm{H} 2 \mathrm{O} 2$-precipitated boehmite from sodium aluminate solutions. J Chem Technol Biotechnol 72:320-328

22. Ho C-Y, Huang C-H (2016) Enhancement of hydrogen generation using waste aluminum cans hydrolysis in low alkaline de-ionized water. Intern J Hydrog Energy 41:3741-3747

23. Martínez SS, Sánchez LA, Gallegos AAÁ, Sebastian PJ (2007) Coupling a PEM fuel cell and the hydrogen generation from aluminum waste cans. Intern J Hydrogen Energy 32:3159-3162

24. Silva CR, Conceição CDC, Bonifácio VG, Filho OF, Teixeira MFS (2009) Determination of the chemical oxygen demand (COD) using a copper electrode: a clean alternative method. J Solid State Electrochem 13:665-669

25. Mohamed MA, Halawy SA (1994) Kinetic and mechanistic study of the non-isothermal decomposition of manganese (II) acetate tetrahydrate. Thermochim Acta 242:173-186

26. Xu J, Chena L, Qu H, Jiao Y, Xie J, Xing G (2014) Preparation and characterization of activated carbon from reedy grass leaves by chemical activation with $\mathrm{H}_{3} \mathrm{PO}_{4}$. Appl Surf Sci 320:674-680

27. Santos DHS, Duarte JLS, Tonholo J, Meili L, Zanta CLPS (2020) Saturated activated carbon regeneration by UV-light, $\mathrm{H}_{2} \mathrm{O}_{2}$ and Fenton reaction. Sep Purif Technol 250:117112

28. Prakash MO, Raghavendra G, Ojha S, Pancha M (2020) Characterization of porous activated carbon prepared from arhar stalks by single step chemical activation method. Mater Today: Proc. https://doi.org/10.1016/j.matpr.2020.05.370

29. El-Katatny EA, Halawy SA, Mohamed MA, Zaki MI (2003) Surface composition, charge and texture of active alumina powders recovered from aluminum dross tailings chemical waste. Powder Technol 132:137-144

30. Devi R, Dahiya RP (2006) Chemical oxygen demand (COD) reduction in domestic wastewater by fly ash and brick kiln ash. Water Air Soil Pollut 174(1-4):33-46

31. Bankole MT, Abdulkareem AS, Tijani JO, Ochigbo SS, Afolabi AS, Roosd WD (2017) Chemical oxygen demand removal from

\section{Authors and Affiliations}

\author{
Adel Abdelkader ${ }^{1}$ - Basem M. Hussien ${ }^{2} \cdot$ Eman M. Fawzy $^{2} \cdot$ Asma A. Ibrahim $^{2}$ \\ 1 Chemistry Department, Faculty of Science, South Valley \\ University, Qena 83523, Egypt \\ 2 Chemistry Department, Faculty of Science, Aswan \\ University, Aswan 81528, Egypt
}

electroplating wastewater by purified and polymer functionalized carbon nanotubes adsorbents. Water Resour Ind 18:33-50

32. Ligaray M, Futalan CM, de Luna MD, Wan M-W (2018) Removal of chemical oxygen demand from thin-film transistor liquidcrystal display wastewater using chitosan-coated bentonite: isotherm, kinetics and optimization studies. J Clean Prod 175:145-154

33. Kaur K, Mor S, Ravindra K (2016) Removal of chemical oxygen demand from landfill leachate using cow-dung ash as a low-cost adsorbent. J Colloid Interface Sci 469:338-343

34. Khellouf M, Chemini R, Salem Z, Khodja M, Zeriri D, Jada A (2020) A new activated carbon prepared from cypress cones and its application in the COD reduction and colour removal from industrial textile effluent. Environ Dev Sustain 2:2. https:// doi.org/10.1007/s10668-020-00944-2

35. Chung H-K, Kim W-H, Park J, Cho J, Jeong T-Y, Park P-K (2015) Application of Langmuir and Freundlich isotherms to predict adsorbate removal efficiency or required amount of adsorbent. J Ind Eng Chem 28:241-246

36. Ahamad KU, Singh R, Baruah I, Choudhury H, Sharma MR (2018) Equilibrium and kinetics modeling of fluoride adsorption onto activated alumina, alum and brick powder. Groundw Sustain Dev 7:452-458

37. He Y, Liao X, Liao L, Shu W (2014) Low-cost adsorbent prepared from sewage sludge and corn stalk for the removal of COD in leachate. Environ Sci Pollut Res 21:8157-8166

38. Nanta P, Kasemwong K, Skolpap W (2018) Isotherm and kinetic modeling on superparamagnetic nanoparticles adsorption of polysaccharide. J Environ Chem Eng 6:794-802

39. Siddiqui SI, Rathi G, Chaudhry SA (2018) Acid washed black cumin seed powder preparation for adsorption of methylene blue dye from aqueous solution: thermodynamic, kinetic and isotherm studies. J Mol Liq 264:275-284

40. Baseri H, Tizro S (2017) Treatment of nickel ions from contaminated water by magnetite based nanocomposite adsorbents: effects of thermodynamic and kinetic parameters and modeling with Langmuir and Freundlich isotherms. Process Saf Environ Prot 109:465-477

41. Bhatnagar A, Jain AK, Mukul MK (2005) Removal of congo red dye from water using carbon slurry waste. Environ Chem Lett 2:199-202

42. Gallo-Cordova A, Silva-Gordillo M, Muñoz GA, Arboleda-Faini X, Streitwieser DA (2017) Comparison of the adsorption capacity of organic compounds present in produced water with commercially obtained walnut shell and residual biomass. J Environ Chem Eng 5:4041-4050

43. Wang W, Wang J (2018) Comparative evaluation of sorption kinetics and isotherms of pyrene onto microplastics. Chemosphere 193:567-573

Publisher's Note Springer Nature remains neutral with regard to jurisdictional claims in published maps and institutional affiliations. 